\title{
Effects of lung volume and fatigue on evoked diaphragmatic phonomyogram in normal subjects
}

\author{
M Petitjean,* J Ripart, $\dagger$ J Couture, F Bellemare
}

\begin{abstract}
Background - A diaphragmatic phonomyogram (PMG) evoked by maximal phrenic nerve stimulation at end expiratory lung volume (FRC) has been previously described as a good index of changes in diaphragmatic contractility with fatigue. A study was undertaken to assess whether this conclusion could be extended to different lung volumes.

Methods - Diaphragmatic compound motor action potentials (CMAPs) were recorded on each side of the chest by the means of surface electrodes placed over the eight intercostal spaces in five healthy subjects. Diaphragmatic PMGs from both sides were recorded with condenser microphones fixed to the skin close to the CMAP recording electrodes. Oesophageal and gastric balloon tipped catheters were employed to measure transdiaphragmatic pressure twitches (TwPDI) which served as the standard measure of changes in diaphragmatic contractility. PMG and TwPDI responses were compared at different lung volumes over inspiratory capacity both before and after fatiguing inspiratory resistive loading.
\end{abstract}

Results - No consistent relationship was found in different subjects or on different days in the same subject between PMG and lung volume or between PMG and TwPDI. However, the PMG:CMAP ratio from both sides at any given lung volume decreased after fatigue in roughly the same proportion as the TwPDI.

Conclusions - These results show that, although PMG can detect changes in diaphragmatic contractility caused by fatigue in normal subjects, lung volume changes need to be controlled and each subject should serve as his or her own control. (Thorax 1996;51:705-710)

Keywords: phonomyogram, diaphragm contractility, fatigue, phrenic nerve stimulation, acoustic myography.

Diaphragmatic fatigue has been recognised as an important factor involved in respiratory failure but is rarely evaluated clinically. ${ }^{1}$ Of the various tests that have been described to evaluate this condition, those that rely on maximal bilateral stimulation of the phrenic nerves and recording of transdiaphragmatic pressure twitches (TwPDI) are perceived as being of potential diagnostic value. ${ }^{2}$ However, the in- vasive nature of PDI measurement restricts the clinical use of this test. A recent study has shown that the diaphragm, as any skeletal muscle, vibrates when it contracts ${ }^{3}$ and the resulting sound waves can be picked up by microphones placed on the surface of the chest. The amplitude of the acoustic signal, also called phonomyogram (PMG), ${ }^{4}$ was found to be proportional to the TwPDI and to decrease with fatigue. Consequently, PMG during bilateral stimulation of the phrenic nerves was considered a good index of diaphragmatic contractility. So far, recording of PMG during bilateral stimulation of the phrenic nerves has been limited to end expiratory lung volume or functional residual capacity (FRC). Several studies have now shown, however, that diaphragmatic contractility, as measured by TwPDI, declines in a linear fashion with increasing lung volume above FRC. ${ }^{5-10}$ The major objectives of this study, therefore, were to determine the effect of lung volume changes on PMG as well as the effect of diaphragmatic fatigue on the PMG recorded at different lung volumes.

\section{Methods}

SUBJECTS

Five normal male volunteers were studied, none of whom had any neuromuscular illness or diaphragmatic injury in their medical history. Four of them were familiar with respiratory physiology procedures and were well trained to perform the diaphragmatic fatigue test efficiently, while the remaining subject had no previous experience with the procedures employed in this study. Three of the subjects were studied twice on two separate occasions.

PHRENIC NERVE STIMULATION

The phrenic nerves were stimulated transcutaneously in the neck with $0.1 \mathrm{~ms}$ square wave pulses delivered by a dual output constant current stimulator (Conterpoint, Dantec Canada, Toronto, Canada). Current intensities in the range of $1-100 \mathrm{~mA}$ could be delivered which was sufficient to produce maximal values of CMAP, PMG, and TwPDI.

\section{RECORDINGS}

CMAP values were recorded with two pairs of surface silver-silver chloride electrodes (Meditrace, Pellet Electrodes, Graphic Controls, Gananoque, Ontario, Canada) taped over the 
eighth intercostal spaces near the costal margin. Right and left PMGs were recorded with two miniature condenser microphones (Archer, Intertan Canada Ltd, Barrie, Ontario, Canada). Each microphone was incorporated into a plexiglass capsule in such a way that the microphone membrane, $6 \mathrm{~mm}$ in diameter, was $2 \mathrm{~mm}$ away from the skin, thus leaving a small air chamber between the microphone and the skin. A small hole $(0.6 \mathrm{~mm}$ internal diameter $)$ was made laterally at this level to allow the pressure in the chamber to equilibrate with atmospheric pressure. A similar device has been used previously ${ }^{11}$ to record breath sounds while avoiding pressure offsets due to gas compression or rarefaction in the chamber when fixing the microphone to the skin. This has been suggested as a potential source of artefacts when recording muscle sounds also. The microphones were fixed with adhesive rings over the eighth intercostal spaces in the anterior axillary line close to the CMAP recording electrodes. Right and left CMAP and PMG recordings were amplified and bandpass filtered at $16-1600 \mathrm{~Hz}$ for CMAPs and $0 \cdot 8-320 \mathrm{~Hz}$ for PMGs, with a multichannel signal conditioner (Counterpoint, Dantec Canada, Toronto, $\mathrm{Ca}$ nada).

The oesophageal (PoEs) and gastric (PGA) pressures were recorded using balloon tipped catheters. The catheters were connected to piezoelectric pressure transducers (Cannon WK6-21c-3/8, Abbott Critical Care Systems, Chicago, Illinois) that recorded PoES and PGA relative to a reference atmospheric pressure. Transdiaphragmatic pressure (PDI) was calculated conventionally by subtracting PoEs from PGA, and served as an index of diaphragmatic force output.

Changes in lung volumes were measured with a bell spirometer equipped with a potentiometer and coupled to a pneumatic occlusion valve (Hans Rudolph, directional valve model 2440, Missouri, USA). For each subject, lung volumes were expressed as a percentage of inspiratory capacity.

\section{PROTOCOL}

All subjects were studied seated. The stimulating current required to stimulate the phrenic nerves maximally was established for each side separately. For subsequent measurements the current intensity was increased by $40 \%$ above that value.

\section{CONTROL MEASUREMENTS}

Recordings were obtained of CMAP, PMG, and TwPDI in response to maximal bilateral phrenic nerve stimulation during relaxation with the airways closed at FRC. At least 24 twitches were recorded and served as controls for all subsequent measurements.

MEASUREMENTS AT DIFFERENT LUNG VOLUMES Maximal bilateral twitches were recorded during relaxation against a closed airway at five different lung volume ranges corresponding to

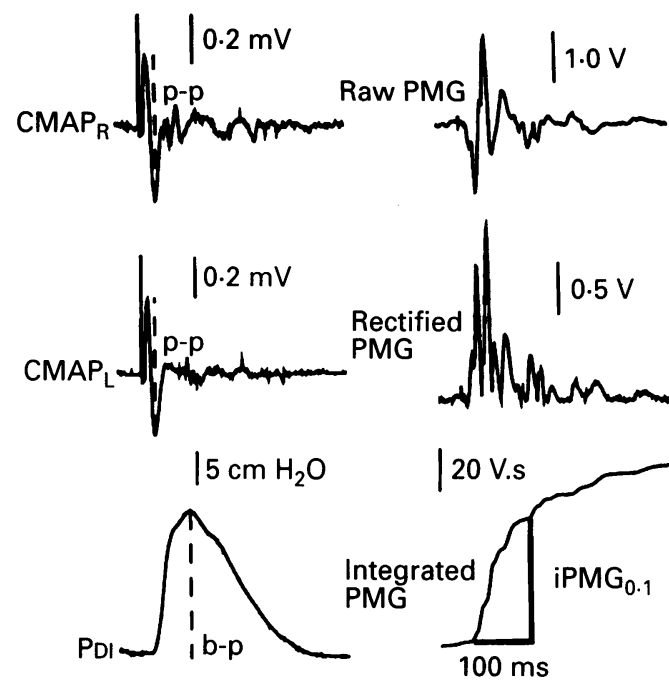

Figure 1 Analysis of the signals. Left column: amplitudes of right and left compound motor action potentials (CMAPs) have been measured peak to peak ( $p-p)$ whereas transdiaphragmatic pressure (PDI) twitch amplitude has been measured baseline to peak $(b-p)$. Right column: right and left phonomyograpic recordings (PMGs) have been rectified and integrated and the integrated value at $100 \mathrm{~ms}$ measured $\left(i P M G_{0 . \nu}\right)$. For all traces stimuli were delivered $50 \mathrm{~ms}$ after onset.

$20 \%$ increments of inspiratory capacity. Between two and 10 twitches were recorded for each subject at each of the designated lung volume ranges. Measurements at different lung volumes were repeated soon after a diaphragmatic fatigue test.

\section{FATIGUE TEST}

To induce diaphragmatic fatigue the subjects were asked to breathe through an inspiratory resistance adjusted to enable the subjects to develop, with each breath, approximately $60 \%$ of their maximal voluntary PDI which was displayed to the subject on a storage oscilloscope. Attempts were also made to control the breathing pattern and the inspiratory to total breathing cycle time ratio ( $\mathrm{TI} / \mathrm{TTOT}=0 \cdot 6)$. This pattern of contraction was maintained until the limit of endurance when subjects felt exhausted and came off the mouthpiece. ${ }^{12}$ For all subjects this occurred within 50 minutes.

\section{ANALYSIS OF DATA}

After amplification, all signals were digitised and sampled at a frequency of $1 \mathrm{kHz}$ and then stored on computer. The following measurements were obtained off line (fig 1): baseline to peak amplitude of TwPDI taken as a reference index of diaphragmatic force output; biphasic CMAP values for which the peak to peak amplitude was measured; PMG signals were rectified and integrated and the value of the integrated signal at $100 \mathrm{~ms}$ after onset $\left(\mathrm{PMG}_{0.1}\right)$ taken as a measure of the intensity of the acoustic signal. This time interval corresponds to the rising phase of TwPDI and includes the major oscillations of the acoustic signal. As preliminary measurements indicated, the value of the integrated PMG signal after $200 \mathrm{~ms}$ and $300 \mathrm{~ms}$ was only $11.5(2 \cdot 3) \%$ and $23.3(3 \cdot 6) \%$ 


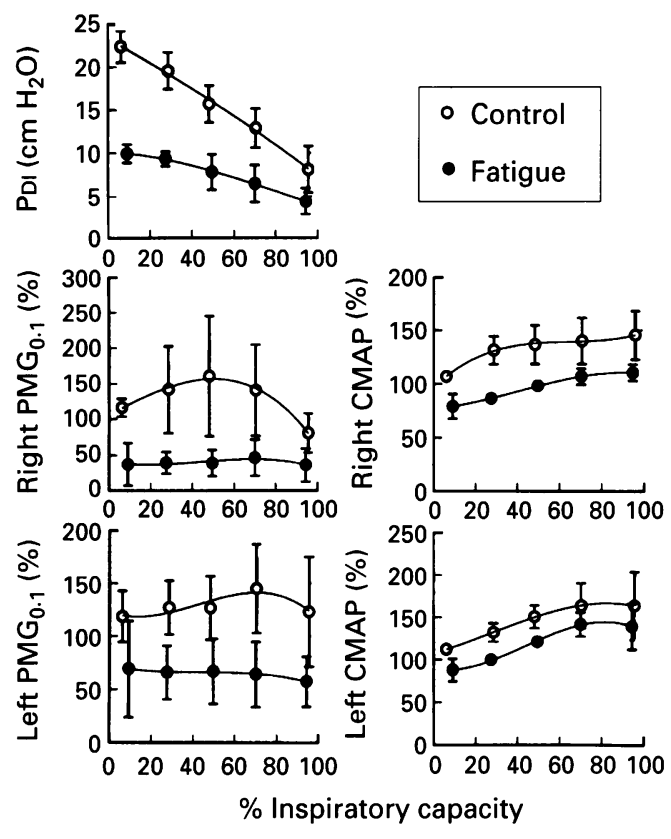

Figure 2 Relationships before and after fatigue between transdiaphragmatic pressure twitch baseline to peak amplitude (PDI), left and right integrated phonomyogram at $100 \mathrm{~ms}\left(P M G_{0 . \nu}\right)$, and peak to peak amplitude of left and right compound motor action potentials (CMAPs) and lung volume changes over inspiratory capacity $(\%$ inspiratory capacity). Bars indicate SE. $A$ third order least square polynomial is drawn through each set of data (solid lines).

higher, respectively, than $\mathrm{PMG}_{0 \cdot 1}$. All values were also expressed as percentage of the control measurements at FRC.

Statistical comparisons were made using paired $t$ tests and analysis of variance as appropriate (Number Cruncher Statistical System, JL Hintze, Kaysville, Utah, USA). Post hoc comparisons were based on Fisher least square deviations and linear regressions using the least square principle were also employed. For all tests a $\mathrm{p}$ value of less than 0.05 was considered statistically significant. Group values are presented as means (SE).

\section{Results}

EFFECT OF CHANGES IN LUNG VOLUME

In all subjects and under all conditions TwPDI decreased progressively with increasing lung volume above FRC (fig 2). This effect of the change in lung volume on TwPDI was highly significant and independent of whether the diaphragm was fresh or fatigued (ANOVA, $\mathrm{p}<$ $0 \cdot 0001)$. By contrast, no consistent pattern could be described for the relationship between $\mathrm{PMG}_{0.1}$ and lung volume. Although in some subjects $P M G_{0.1}$, like TwPDI, declined with increasing lung volume, in others $P_{M G_{0.1}}$ increased with increasing lung volume and, in yet other subjects, both increasing and decreasing trends were observed as a function of lung volume. When group results were considered, changes in lung volume had no significant effect on the $P M G_{0.1}$ from either the right or left side (ANOVA, $\mathrm{p}>0.02$ ). As a result of this intersubject variability, no systematic relationship could be described between $\mathrm{PMG}_{0 \cdot 1}$ and TwPDI with changes in lung volume. In-

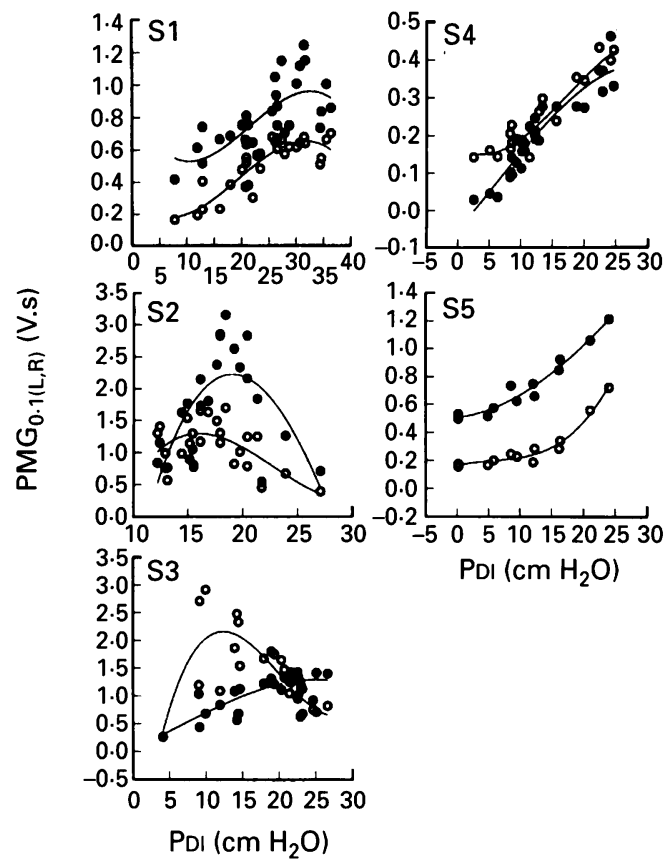

Figure 3 Relationships for each subject (S1-S5) between integrated phonomyogram value at $100 \mathrm{~ms}\left(\mathrm{PMG}_{0 . \nu}\right)$ from left $(\bigcirc)$ and right $(O)$ costal diaphragm and transdiaphragmatic pressure twitch amplitude (PDI). A third order least square polynomial is drawn through each set of data.

dividual relationships are shown in fig 3. A third order polynomial appeared to fit these relationships best. Positive relationships between $P_{M G_{0 \cdot 1}}$ and TwPDI were found on both sides in three subjects ( $1, S 4, S 5)$ and on one side in another subject (S3), whereas in the other cases the PMG eventually declined despite further increases in TwPDI. Although this was not systematically investigated, day to day variability appeared to be greater for $P M G_{0 \cdot 1}$ than for TwPDI (fig 4).

As can be seen in fig 2, both right and left CMAP values increased with increasing lung volume. This effect of changes in lung volume was statistically significant and independent of whether the diaphragm was fresh or fatigued (ANOVA, $\mathrm{p}<0.05$ ).

\section{EFFECT OF FATIGUE}

In all subjects TwPDI decreased after inspiratory loading indicating that their diaphragm was fatigued. As can be seen in fig 2, the relationship between TwPDI and the lung volume remained negatively sloped but was shifted downwards after fatigue. This shift for the group was highly significant and independent of lung volume (ANOVA, $\mathrm{p}<0.0001$ ).

Both left and right CMAP values tended to decrease after fatigue. The decline with fatigue also tended to be greater on the right side $(35 \%)$ than on the left $(22 \%)$. The analysis of variance showed this effect of fatigue to be statistically significant and independent of changes in lung volume (ANOVA, $\mathrm{p}<0 \cdot 02$ ).

Irrespective of their shape, the relationship between the $P M G_{0.1}$ and the lung volume, like that with the TwPDI, was shifted downwards 

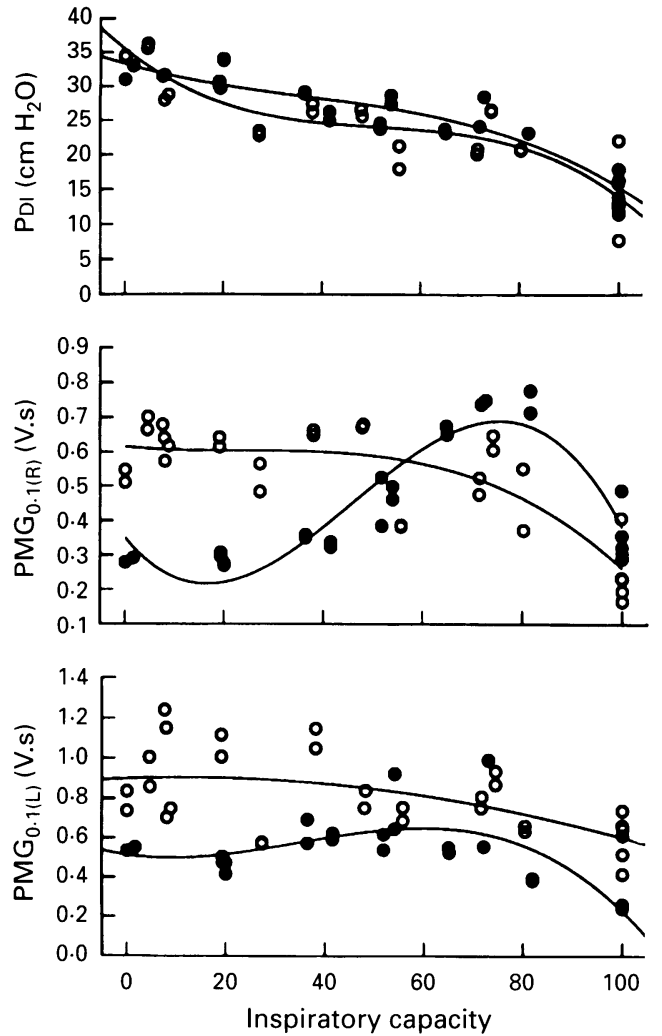

Figure 4 Relationships in one subject (S1) between transdiaphragmatic pressure twitch baseline to peak amplitude (PDI) and integrated phonomyogram at $100 \mathrm{~ms}$ $\left(P M G_{0 .}\right)$ from right $(R)$ and left $(L)$ costal diaphragm and lung volume changes over inspiratory capacity $(\%$ inspiratory capacity) obtained on two separate days ( O). The line of best fit through each set of data is a third order least square polynomial.

after fatigue in all subjects. For the group this shift was highly significant on both sides and independent of changes in lung volume (ANOVA, $p<0.001)$. However, owing to the observed changes in the size of the CMAP on both sides, no direct comparison could be made between changes in TwPDI and in $\mathrm{PMG}_{0 \cdot 1}$. To

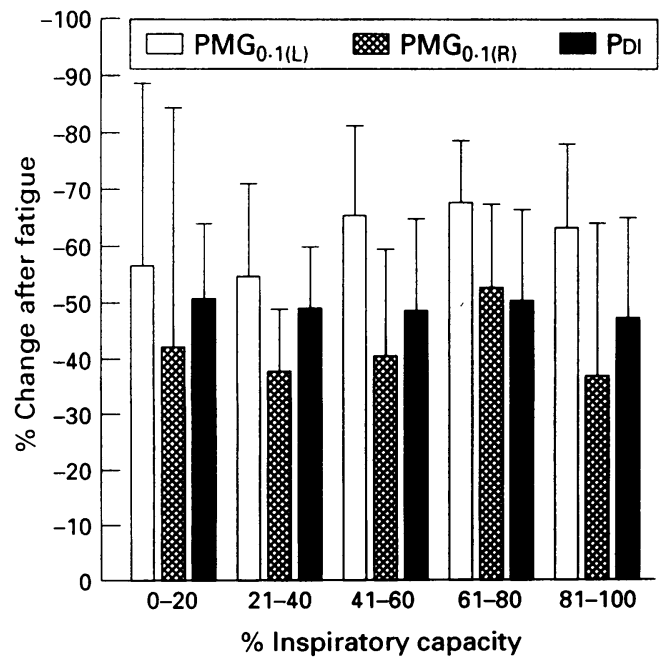

Figure 5 Bar diagram comparing the mean (SE) percentage change after fatigue of the left $(L)$ and right percentage change after fatigue of the left $(L)$ and compound motor action potential peak to peak amplitude ratio $\left(P M G_{0.1}: C M A P\right)$ and with the transdiaphragmatic pressure twitch baseline to peak amplitude (PDI) at five different lung volume ranges over inspiratory capacity (\% inspiratory capacity). overcome this difficulty the ratio of $\mathrm{PMG}_{0 \cdot 1}$ to CMAP was calculated separately for each side. This is possible because PMG has been shown previously to be proportional to the size of the $\mathrm{CMAP}^{3}$ In fig 5 the change in this ratio with fatigue on both sides is compared with the changes in TwPDI observed at the corresponding lung volumes. As can be seen, the changes in PDI and in both the right and left $\mathrm{PMG}_{0 \cdot 1}$ :CMAP ratios with fatigue were independent of lung volume. The $\mathrm{PMG}_{0.1}$ :CMAP ratio tended to decrease more on the left side than on the right, a difference that almost reached significance $(p=0.05)$. The change in TwPDI at any given lung volume appeared to be intermediate between those of the left and right $\mathrm{PMG}_{0 \cdot 1}: \mathrm{CMAP}$ ratios and was not significantly different from them.

\section{Discussion}

We have shown that, in normal subjects, it is possible to observe the presence of diaphragmatic fatigue by recording the PMG in response to an artificial nerve stimulus at any given lung volume. However, the PMG also varied with lung volume and amongst subjects. In order to use this test, lung volume must therefore be controlled and each subject should serve as his own control.

EFFECT OF LUNG VOLUME ON $\mathrm{PMG}_{0 \cdot 1}$

The PMG has been shown previously to be proportional to the strength of contraction of both limb ${ }^{413.17}$ and diaphragm muscles. ${ }^{3}$ In the present study the strength of diaphragmatic contractions (or TwPDI) was varied by increasing the lung volume. In some cases positive relationships were found between $P \mathrm{MG}_{0.1}$ and TwPDI indicating that, in these instances too, PMG could reflect the strength of diaphragmatic contractions. In other cases, however, the relationships were curvilinear or even parabolic, with $\mathrm{PMG}_{0 \cdot 1}$ reaching a maximum at intermediate values of TwPDI. In these instances other factors must have come into play to alter the relationship between $\mathrm{PMG}_{0.1}$ and TwPdi.

Several factors could account for this variability and it is not possible at present to distinguish between them. Studies on isolated frog muscles in vitro have shown that the acoustic response/length relationship has a similar shape to the twitch tension/length relationship, but that it is shifted along the length axis towards shorter muscle fibre lengths. ${ }^{21-23}$ Thus, the maximum acoustic response occurs at a shorter length than the twitch tension ${ }^{21}$ and, as a result, the relationship between $P M G_{0.1}$ and TwPDI is unpredictable. Alternatively, as TwPDI is dependent on both the tension developed and the shape of the diaphragm, ${ }^{192425}$ changes in diaphragmatic shape at different lung volumes or in the configuration of the chest wall could conceivably alter the $P M G_{0.1}$ for a given TwPDI. Other factors are more likely to be involved. In order to be recorded at the surface of the chest wall, the lateral vibrations of the diaphragm must be transmitted to the structures 
that surround it. The mechanical properties of those structures located between the diaphragm and the microphones should thus play an important part in determining the amplitude of the acoustic signal recorded at the surface of the chest as was shown for the heart/thorax acoustic system in dogs, ${ }^{26}$ and this may change as a function of lung volume. The PMG could also be sensitive to the microphone placement, and this too could vary in different subjects or on different days in the same subject. Although the position of the microphones was fixed in a given experiment, the ribs could move. A combination of all these factors therefore probably explains the variable relationships observed in our study between $P_{M G}$ and TwPDI when the lung volume was varied.

\section{EFFECT OF LUNG VOLUME ON CMAP}

Significant increases were seen in the size of the left and right CMAP with increasing lung volume. As the phrenic nerve stimulus was set to be supramaximal at FRC, it can reasonably be assumed to have remained the same throughout. The observed changes with lung volume could have been artefactual in origin as has been shown previously with oesophageal electrode recordings. ${ }^{27}$

EFFECT OF FATIGUE ON CMAP AND PMG P.1 $_{0}$ The changes in CMAP observed after fatigue are more difficult to explain. A failure of neuromuscular propagation would seem unlikely in view of earlier studies in humans. ${ }^{2829}$ Changes in chest wall configuration at a given lung volume after fatigue could also have altered the size of the CMAP, despite the maintenance of a maximal nerve stimulus. This possibility also seems unlikely in view of our finding that, when corrected for the change in CMAP size $\left(\mathrm{PMG}_{0.1}: \mathrm{CMAP}\right)$, the mean of the left and right corrected $\mathrm{PMG}_{0.1}$ changed with fatigue in roughly the same proportion as TwPDI (fig 5). This finding also supports the use of PMG as a non-invasive index of changes in diaphragmatic contractility with fatigue. ${ }^{3}$ Indeed, the $\mathrm{PMG}_{0 \cdot 1}$ : CMAP ratio is a measure of the effectiveness of the excitation/contraction coupling process that should be uniquely affected by events which occur beyond the neuromuscular junction and the sarcolemma. However, the fact that both the numerator and the denominator of this ratio were affected by changes in lung volume restricts the applicability of this test. This is a difficulty that is shared by all tests of changes in diaphragmatic contractility with fatigue so far described. Nevertheless, there could be advantages to the use of $P M G_{0.1}$ when lung volume changes can be controlled. The test is non-invasive and, because $P_{M G}$ is measured in response to an external stimulus, it is independent of effort. Because the PMG is proportional to the CMAP, a submaximal stimulus can be employed which simplifies the testing procedure while reducing the discomfort to the subject. ${ }^{3}$ Furthermore, because the response is the same during unilateral and bilateral stimulation, ${ }^{3}$ it is only necessary to stimulate one phrenic nerve at a time which further simplifies the testing procedure. It thus becomes possible to investigate regional differences in diaphragmatic contractility between the left and the right sides. We wish to emphasise, however, that this test has so far been employed only in well controlled laboratory conditions in normal volunteers, and that, in view of the many factors that may affect the PMG signals outlined above, it is premature to judge the suitability of this test for clinical patients.

In conclusion, this study has shown that, when changes in the lung volume can be controlled or when the lung volume remains constant, acute changes in diaphragmatic contractility caused by fatigue can be evaluated in normal subjects by recording the PMG from either the right or left hemidiaphragm in response to an external stimulus. This is a simple non-invasive procedure which, when combined with simultaneous recording of the CMAP, can assess acute changes in the excitation/contraction coupling of the diaphragm. This technique also offers the possibility of evaluating changes in the contractility of each hemidiaphragm separately. Future studies should indicate whether or not this test can be clinically useful.

We wish to thank $\mathrm{Mr}$ Serge Filiatrault for his technical assistance. Preliminary results of this study have been presented at the annual meeting of the American Thoracic Society, Boston in May $1994 .^{30}$ This study was supported by the Medical Research Council of Canada and the Respiratory Health Network of Centers of Excellence.

1 Roussos C, Macklem PT. Diaphragmatic fatigue in man. $\mathcal{f}$ Appl Physiol 1977;43:189-97.

2 NHLBI Workshop on Respiratory Muscle Fatigue. Report of the Respiratory Muscle Fatigue Workshop Group. $\mathrm{Am}$ Rev Respir Dis 1990;142:474-80.

3 Petitjean M, Bellemare F. Phonomyogram of the diaphragm during unilateral and bilateral phrenic nerve stimulation during unilateral and bilateral phrenic nerve stimulation

4 Foix C, Thévenard A, Dupasquier C. Enregistrement du bruit musculaire par le galvanomètre à corde et l'amplificateur à basse fréquence (phonomyogrammes). Données relatives à la contracture et à la contraction. Contraction cinétique et contraction statique (posturale). $C R$ Soc Biol 1923;89:733-5.

5 Hubmayr RD, Litchy WJ, Gay PC, Nelson SB. Transdiaphragmatic twitch pressure. Effects of lung volume and chest wall shape. Am Rev Respir Dis 1989;139:647-52.

6 Johnson BD, Babcock MA, Suman OE, Dempsey DA. Exercise-induced diaphragmatic fatigue in healthy subjects. F Appl Physiol 1993;460:385-405.

7 Mier A, Brophy C, Moxham J, Green M. Influence of lung volume and rib cage configuration on transdiaphragmatic pressure during phrenic nerve stimulation. Respir Physio 1990;80:193-202.

8 Similowski T, Yan S, Gauthier AP, Macklem PT, Bellemare F. Contractile properties of the human diaphragm during chronic hyperinflation. $N$ Engl $f$ Med 1991;325: 917-23.

9 Smith J, Bellemare F. Effect of lung volume on in vivo contraction characteristics of human diaphragm. $\mathcal{f} A p p l$ Physiol 1987;62:1893-900.

10 Yan S, Similowski T, Gauthier AP, Macklem PT, Bellemare F. Effect of fatigue on diaphragmatic function at differen lung volume. $\mathcal{F}$ Appl Physiol 1992;72:1064-7.

1 Ploy Song Sang Y, Martin RR, Ross WRD, Loudon RG Macklem PT. Breath sounds and regional ventilation. $A m$ Rev Respir Dis 1977;117:187-99.

12 Bellemare F, Grassino A. Effect of pressure and timing of contraction on human diaphragm fatigue. $\mathcal{f} A$ ppl Physiol 1982;53:1190-5.

13 Barry DT, Geiringer SR, Ball RD. Acoustic myography: a non-invasive monitor of motor unit fatigue. Muscle Nerve non-invasive mon
1985;8:189-94.

14 Maton B, Petitjean M, Cnockaert JC. Phonomyogram and electromyogram relationships with isometric force reinvestigated in man. Eur 7 Appl Physiol 1990;60:194-201.

15 Petitjean M, Maton B, Cnockaert JC. Evaluation of human dynamic contraction by phonomyography. $\mathcal{F}$ Appl Physiol 1992;73:2567-73.

16 Barry DT. Muscle sounds from evoked twitches in the hand. Arch Phys Med Rehab 1991;72:573-5. 
17 Barry DT, Im DJ, Hill T. Muscle fatigue measured with evoked muscle vibrations. Muscle Nerve 1992;15:303-9.

18 Braun NMT, Arora NS, Rochester DF. Force-length relationship of the normal human diaphragm. $\mathcal{f}$ Appl Physiol 1982;53:405-12.

19 Kim MJ, Druz WS, Danon J, Machnach W, Sharp JT. Mechanics of the canine diaphragm. F Appl Physiol 1976; 41: $369-82$

20 Loring SH, Mead J, Griscom NT. Dependence of diaphragmatic length on lung volume and thoracoabdomina configuration. $\mathcal{F}$ Appl Physiol 1985;59:1961-70.

21 Barry DT. Acoustic signals from frog skeletal muscle. Biophys $\mathcal{F}$ 1987;51:769-73.

22 Dobrunz LE, Pelletier DG, McMahon TA. Muscle stiffness measured under conditions simulating natural sound production. Biophys $\mathcal{F}$ 1990;58:557-65.

23 Frangioni JV, Kwan-Gett TS, Dobrunz LE, McMahon TA The mechanism of low-frequency sound production in

24 Loring SH, Mead J. Action of the diaphragm on the rib cage inferred from a force-balance equation. $7 \mathrm{Appl}$ Physio 1982;53:756-60.
25 Gauthier AP, Verbanck S, Estenne M, Segebarth C, Macklem PT, Paiva $M$. Three-dimensional reconstruction of the in vivo human diaphragm shape at different lung of the in vivo human diaphragm shape at

26 Durand LG, Genest J Jr, Guardo R. Modeling of the transfer function of the heart-thorax acoustic system in dogs. IEEE Trans Biomed Eng 1985;BME-32:592-601.

27 Gandevia SC, McKenzie DK. Human diaphragmatic EMG: changes with lung volume and posture during supramaximal phrenic nerve stimulation. F Appl Physiol 1986; 60:1420-8.

28 Bellemare F, Bigland-Ritchie B. Central components of diaphragmatic fatigue assessed by phrenic nerve stimulation. $\mathcal{f}$ Appl Physiol 1987;62:1307-16.

29 McKenzie DK, Bigland-Ritchie B, Gorman RB, Gandevia SC. Central and peripheral fatigue of human diaphragm and limb muscles assessed by twitch interpolation. $\mathcal{F}$ Physiol (London) 1992;454:643-56.

30 Petitjean M, Ripart J, Couture J, Bellemare F. Influence of lung volume and fatigue on diaphragmatic phonomyogram. Am Rev Respir Dis 1994;149:A130. 